\title{
Research Paper \\ The Effect of the Different Kinds of Capital on Economic Growth of Selected Provinces of Iran
}

\author{
* Parvaneh Kamali Dehkordi ${ }^{1}$, , Ali Nazari Zaniani² ${ }^{\circledR}$, Seyed Nezamuddin Makiyan³ ${ }^{\mathbb{1}}$, \\ Fatemeh Dehghani ${ }^{4}$
}

1. PhD. in Economics, Assistant Professor, Department of Economics, ShahreKord Branch, Payam-e Noor University, ShahreKord, Iran. 2. PhD. Student of Economics, Department of Economics, School of Economics, Management \& Social Sciences, Shiraz University, Shiraz, Iran.

3. $\mathrm{PhD}$. in Economics, Associate Professor, Department of Economics, Management \& Accounting, Faculty of Humanities and Social Sciences, Yazd University, Yazd, Iran.

4. MA. in Economics, Department of Economics, Management \& Accounting, Faculty of Humanities and Social Sciences, Yazd University, Yazd, Iran.

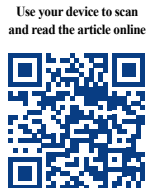

ditation: Kamali Dehkordi, P., Nazari Zaniani, A., Nezamuddin Makiyan, S., \& Dehghani, F. (2019). [The Effect of the Different Kinds of Capital on Economic Growth of Selected Provinces of Iran (Persian)]. Quarterly Journal of the Macro and Strategic Policies, 7(1), 66-85. https://doi. org/10.32598/JMSP.7.1.66

https://doi.org/10.32598/JMSP.7.1.66

Received: 08 Nov 2017

Accepted: 18 Jun 2018

Available Online: 01 Apr 2019

\section{A BSTRACT}

This paper has studied the role of physical, human, and social capital on the economic growth of 20 selected provinces of Iran by using the augmented augmented-Solow model expanded by Ishi and Swada. Mankiw, Romer, and Weil regression equation derived from the research model is specified according to two classes of unit root tests for the panel models in two forms and is estimated by the generalized method of moment for dynamic panel data (GMM/DPD) and orthogonal deviation technique. The results of the estimation of the first form of regression analysis indicate that $1 \%$ increase in growth rate of national saving leads to $0.57 \%$ increase in growth rate of per capita gross domestic product (GDP), $1 \%$ increase in the number of university students (as representative of human capital saving) leads to $0.035 \%$ increase in per capita GDP growth rate, and $1 \%$ increase in growth rate of closed cases of returned checks (as representative of negative social capital saving) leads to $0.038 \%$ decrease in per capita GDP growth rate. The results of the estimation of the second form of the regression analysis confirm the role of three factors of physical, human, and social capital on the economic growth of studied provinces.

JEL Classification: $\mathrm{O} 11, \mathrm{H} 54, \mathrm{R} 10$
Key words:

Economic growth, Physical capital, Human capital, Social capital

* Corresponding Author:

Parvaneh Kamali Dehkordi, PhD.

Address: Department of Economics, ShahreKord Branch, Payam-e Noor University, ShahreKord, Iran.

Tel: +98 (31) 3812776

E-mail: parvanehkamali@gmail.com 


\section{اثر انواع سرمايه بر رشد اقتصادى استانهاى منتخب ايران}

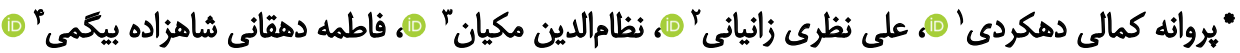
1 - دكتراى اقتصاد، استاديار، كروه اقتصاد، واحد شهركرد، دانشكاه ئيام نور، شهركرده ايران.

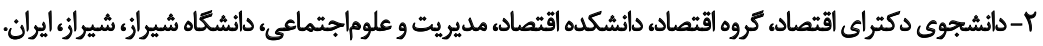

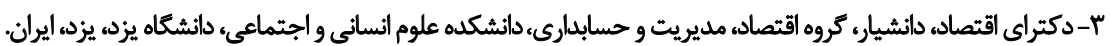

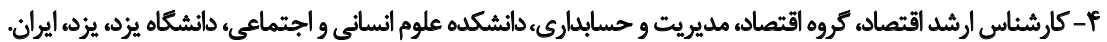

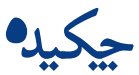

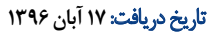

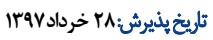

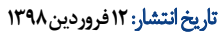

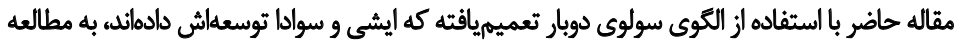

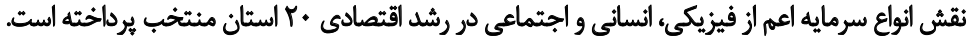

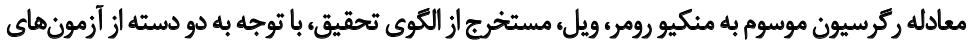

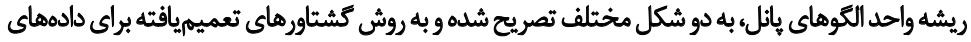

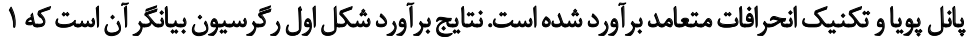

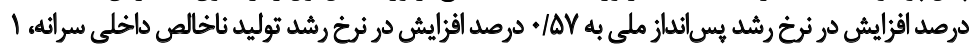

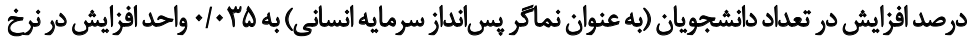

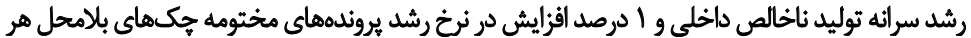

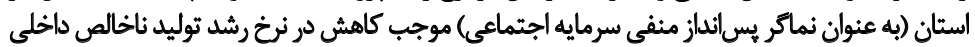

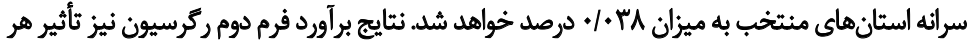

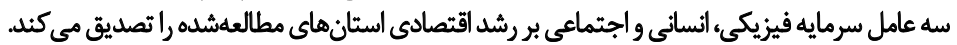

كا: رشد اقتصادى، سرمايه فيزيكي، سرمايه انساني، سرمايه إجتماعى انسي

* نويسنده مسئول: دكتر يروائه كمالي دهكردي مئي

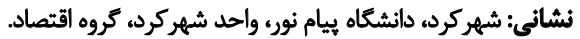
تلفن: تئي : بست الكترونيكي: parvanehkamali@gmail.com 


\section{douso}

همه مكاتب اقتصادى سرمايه را به عنوان عامل كليدى براى رشد اقتصادى تلقى مى كنند و در اغلب الگوهاى

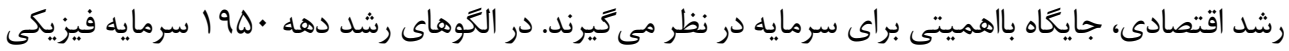

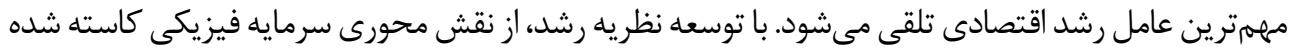

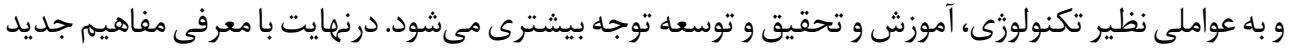

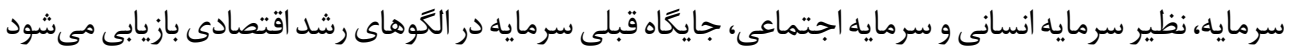

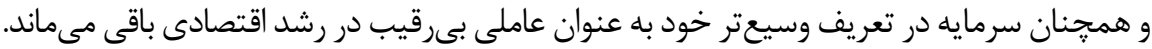

براى ايجاد توليد اقتصادى ضرورت دارد تركيبى از انواع سرمايه اعم از فيزيكى، انسانى و اجتماعى در كنار

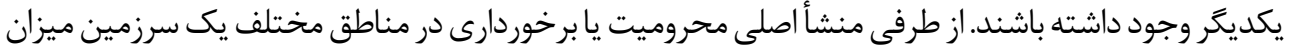

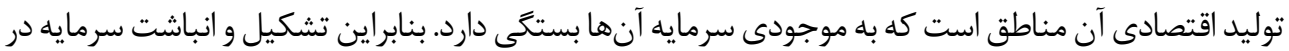

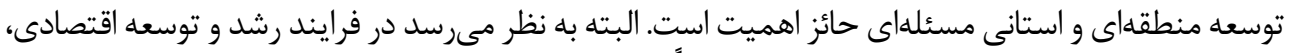

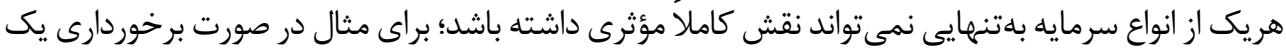

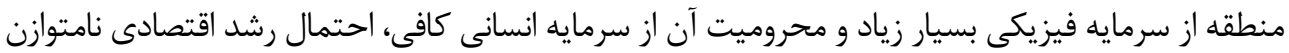

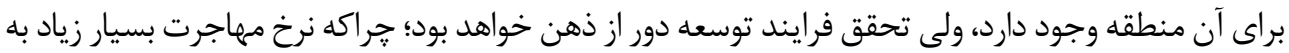

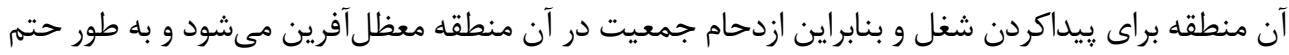

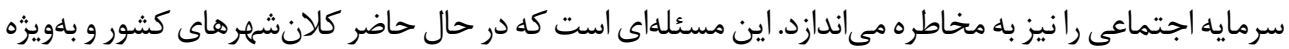

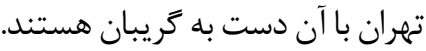

در مناطق و استانهاى حاشيهاى به دليل توسعه آموزش عالى، سرمايه انسانى رشدى بيش از حد و نامتوازن

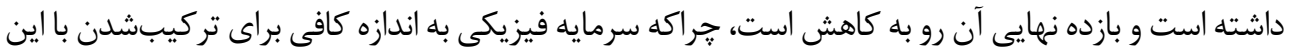

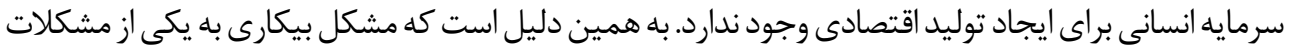

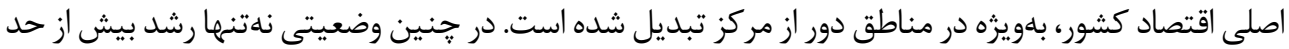

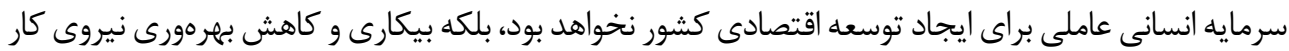

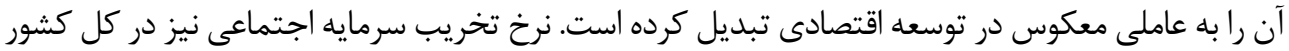

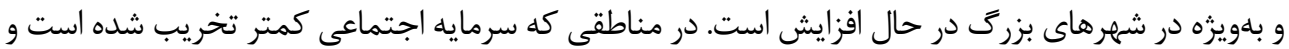

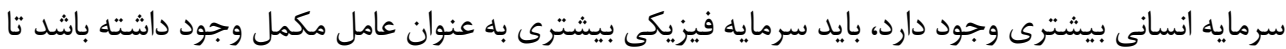

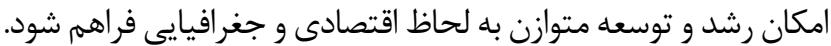

انجام اين يزوهش از حيث بودجهريزى، برنامهريزى منطقهاى و اجراى طرحهاى آمايش منطقهاى حائز

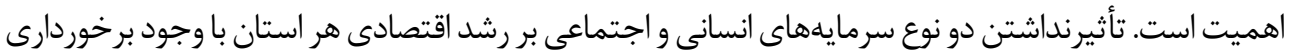

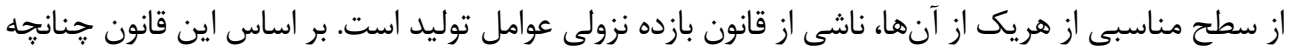

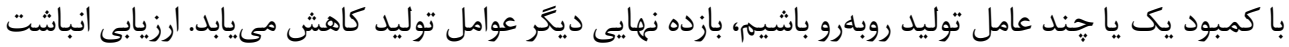

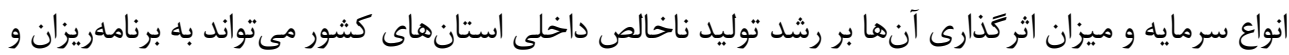




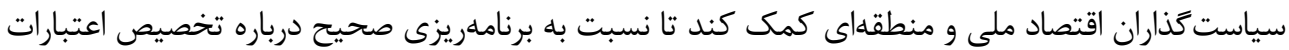

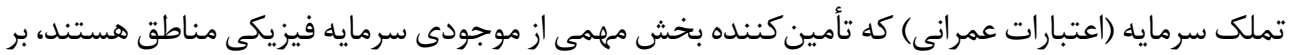

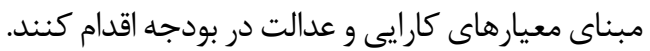

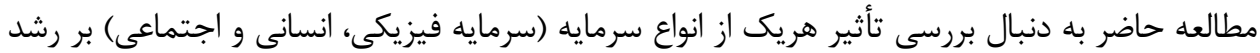

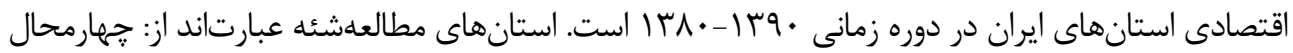

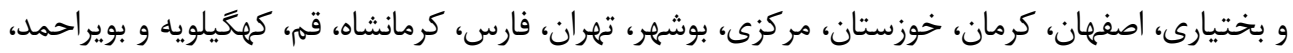

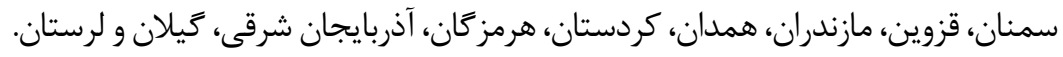

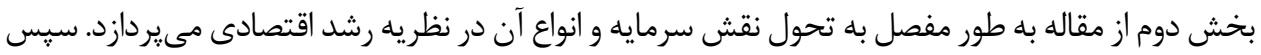

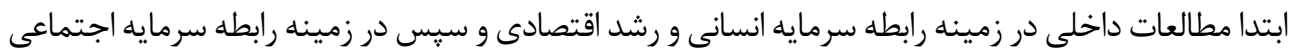

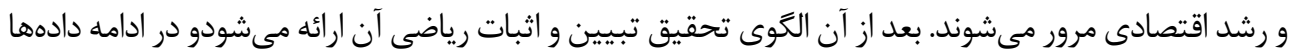

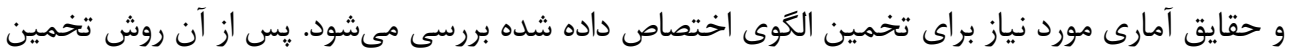

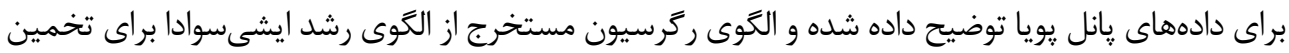

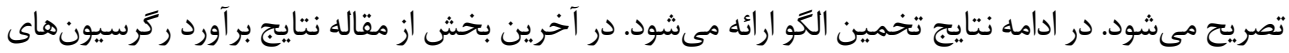
تصريحشده تحليل خواهد شد.

\section{| - 1 إيبات موضوع}

\section{1- - - روايتى از تحول نقش سرمايه و انواع آن در نظريه رشد اقتّادى}

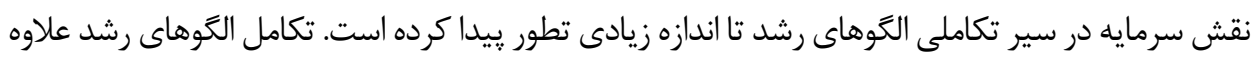

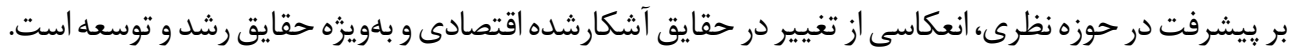

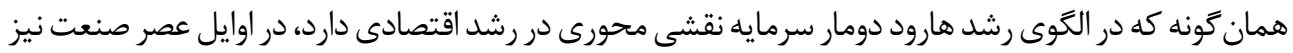

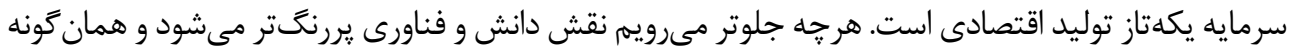

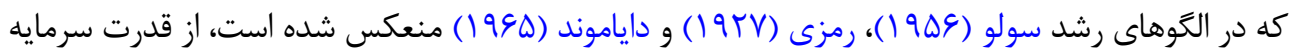

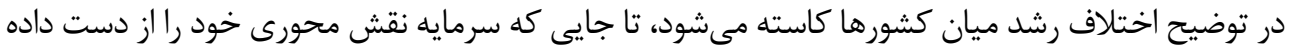

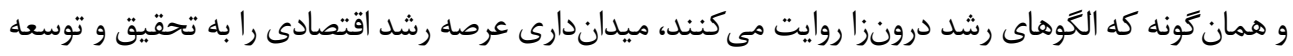

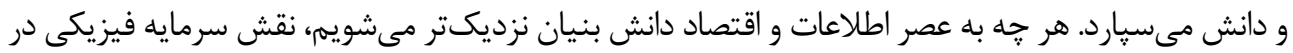
توليد اقتصادى كمرنغتر مى مودئ

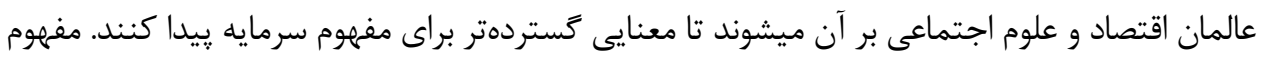

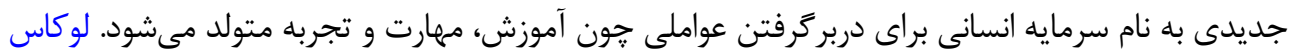

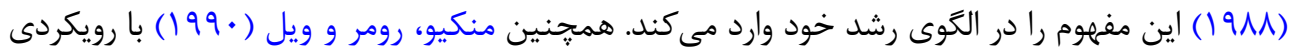

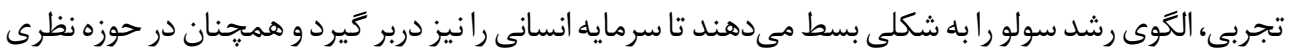


مفهوم سرمايه، بسط داده مىشود تا مفهوم سرمايه اجتماعى به منظور دربر گرفتن عوامل نهادى و فرهنگى تهى

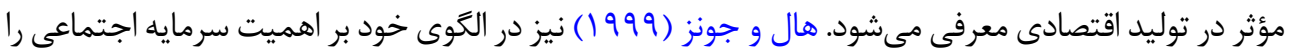

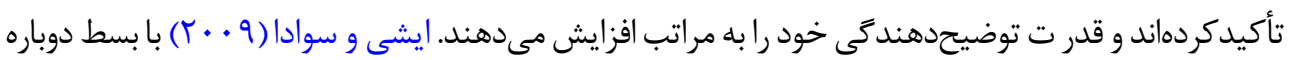
الكوى سولو بر اساس كار منكيو، رومر و ويل (·99 (1) مفهوم گستردهاى از سرمايه شامل سرمايه فيزيكى،

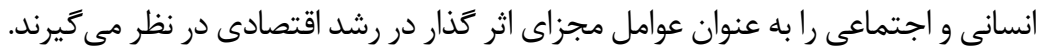

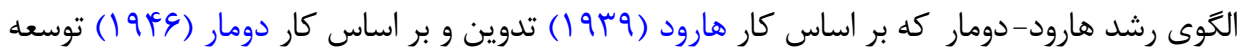

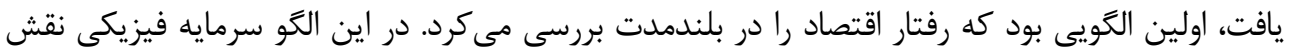

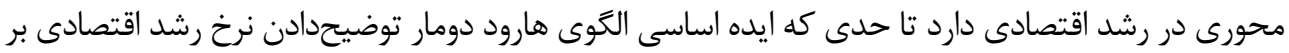

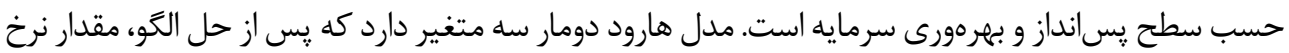

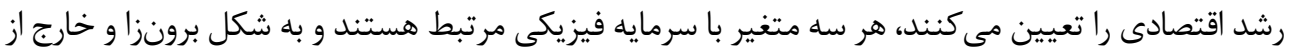

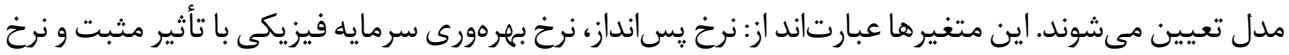

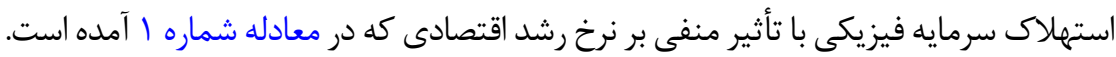

$$
\dot{Y}=\frac{\Delta Y}{Y}=s c-\delta
$$

از نتايج حائز اهميت اين الخو برابرى نرخ رشد سرمايه فيزيكى و نرخ رشد توليد ملى است. الكوى سولو نيز

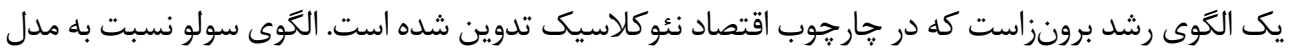

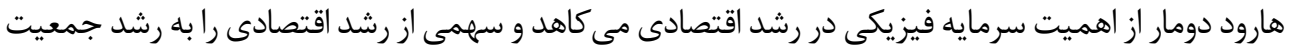

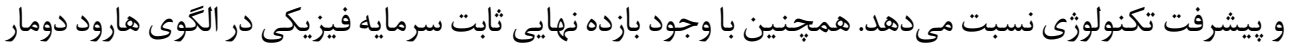

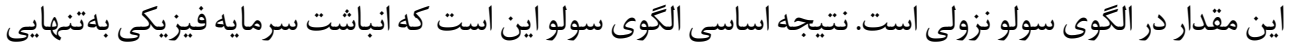

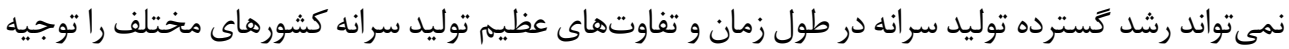

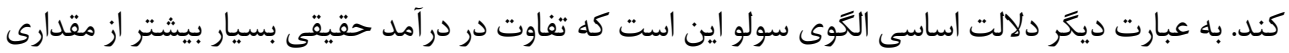

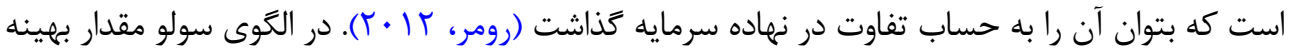

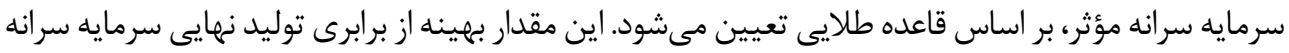

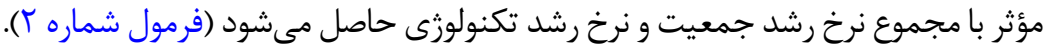

$$
f^{\prime}\left(k_{G . R}\right)=n+g
$$

مقدار سرمايه سرانه مؤثر بلدستآمده از قاعده طلايى، مقدارى است كه به ازاى آن مصرف سرانه مؤثر حداكثر

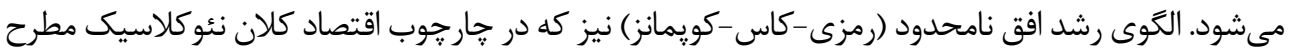

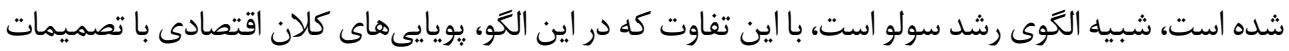




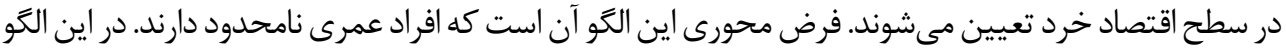

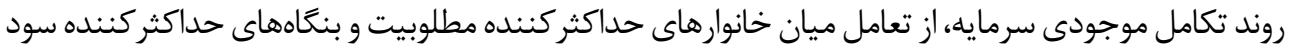

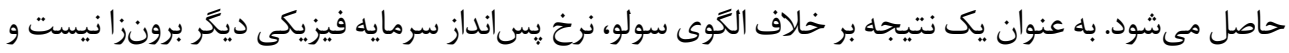

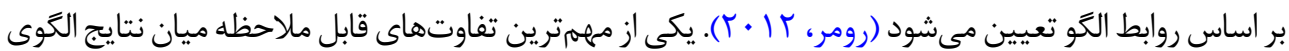

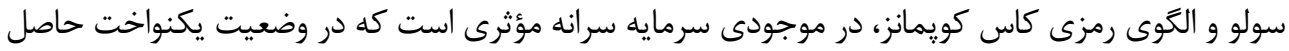

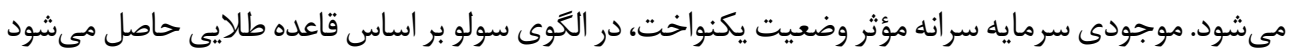

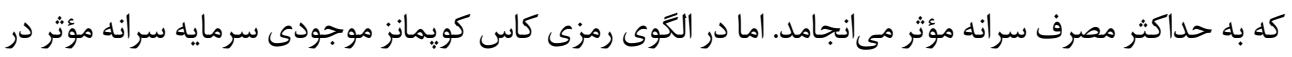

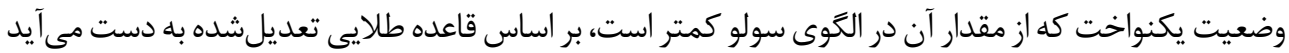

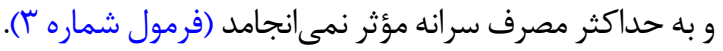

\section{$f^{\prime}\left(k_{M . G . R}\right)=n+g+\rho$}

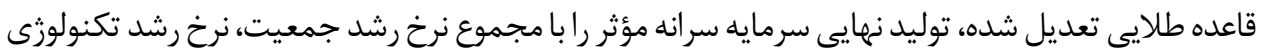

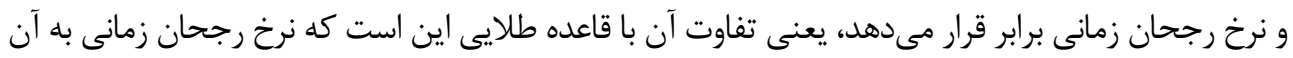

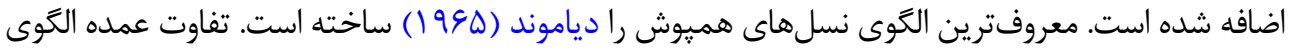

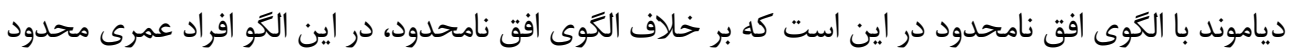

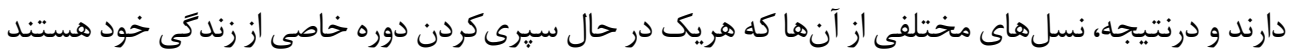

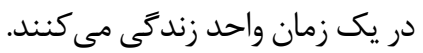

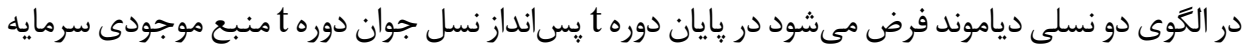

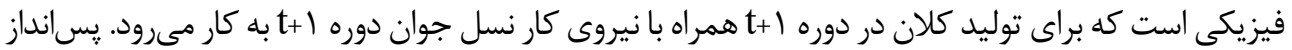

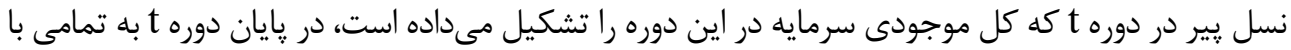

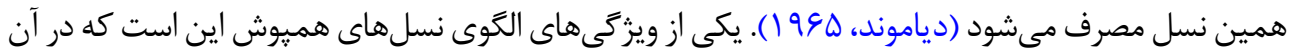

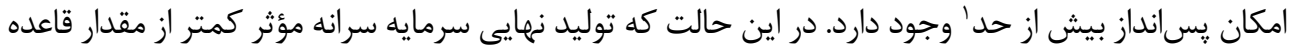

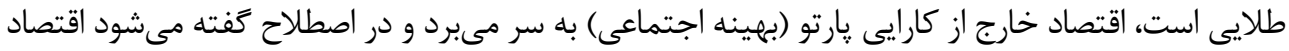

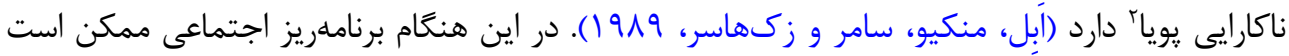

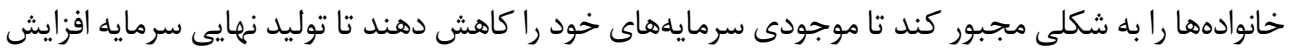

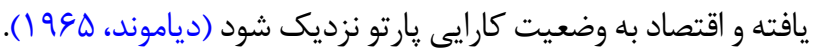

1. Over saving

2. Dynamic inefficiency 


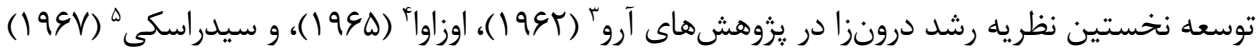

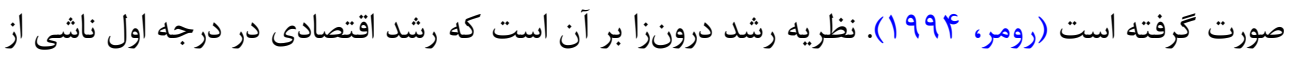

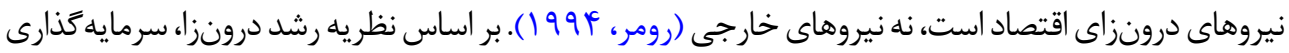

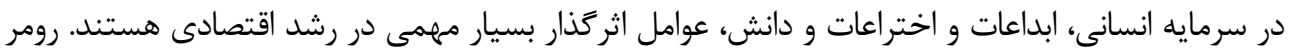

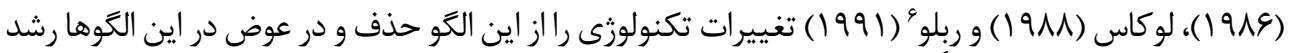

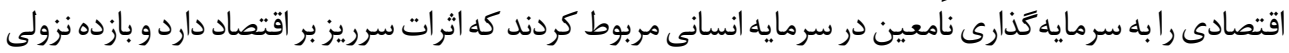

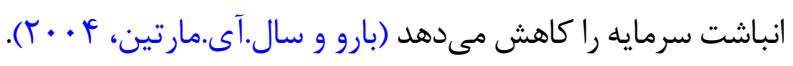

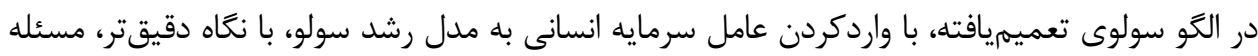

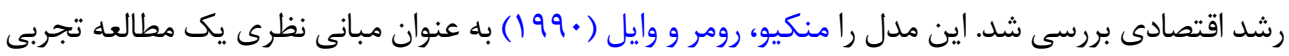

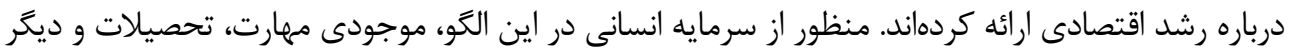

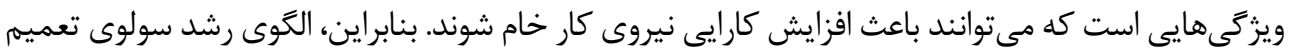

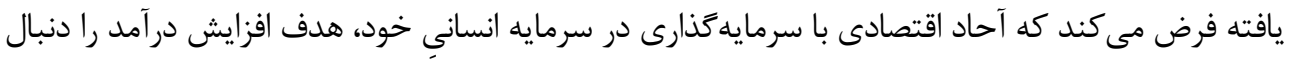

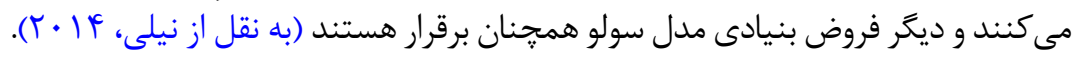

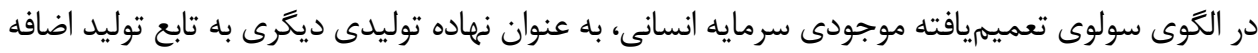

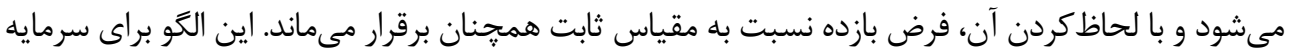

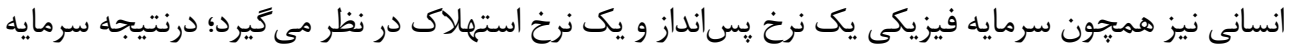

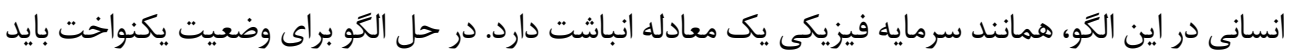

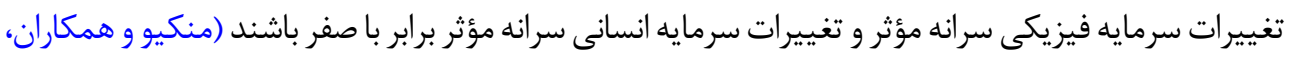

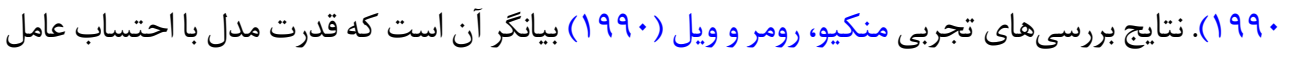

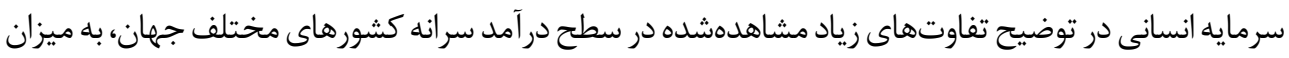

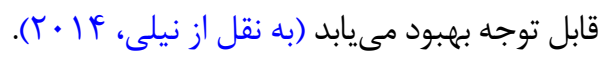

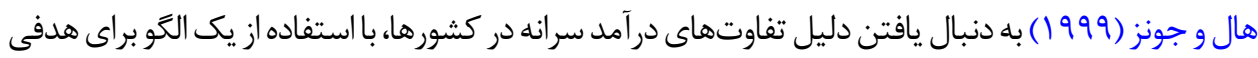

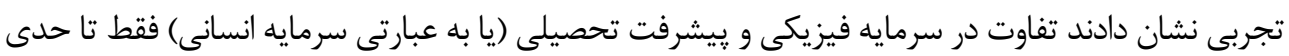

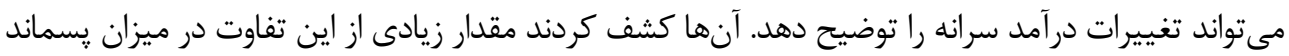

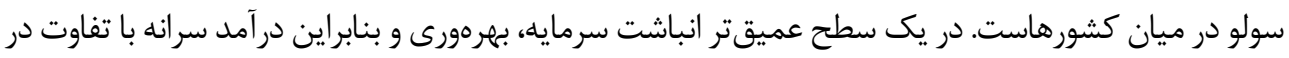

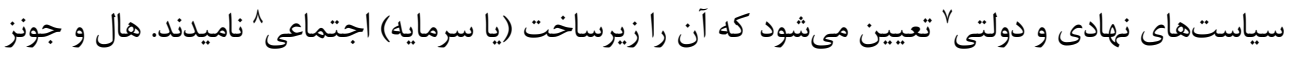
3. Arrow
4. Uzawa
5. Sidrauski
6. Rebelo
7. Institutions and government policies
8. Social infrastructure (or capital) 
سرمايه اجتماعى را به عنوان يك عامل درونزا در نظر گرفتند كه از نظر تاريخى با مكان و عوامل ديگرى همجون زبان حاصل مىشود (هال و جونز، 1999 (1).

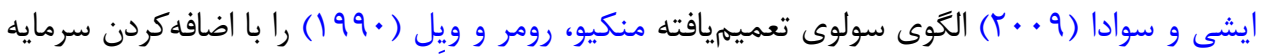

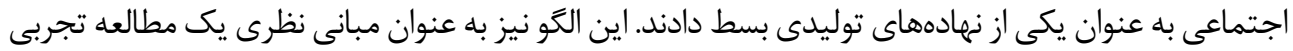

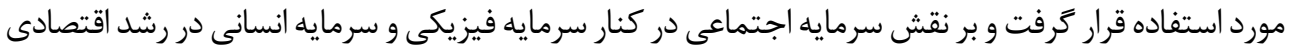

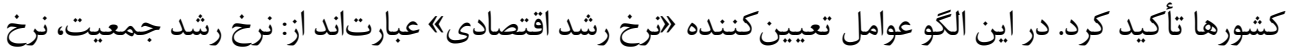

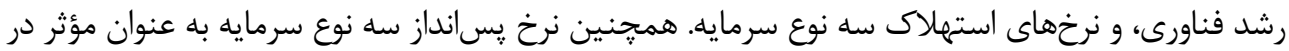

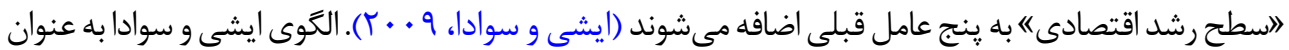
مبناى مطالعه حاضر استفاده شده است.

\section{r-1}

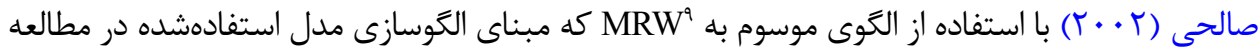

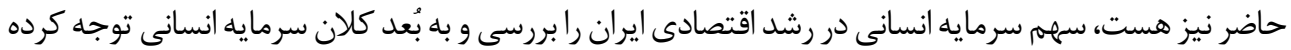

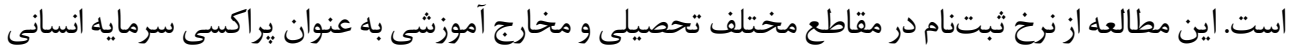

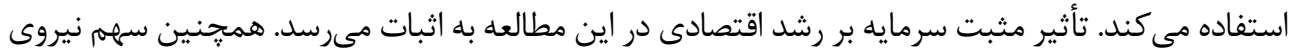

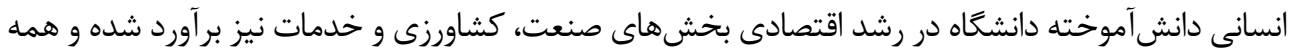

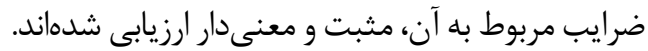

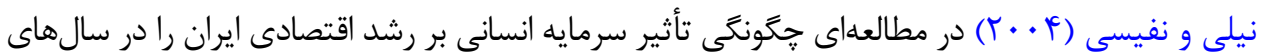

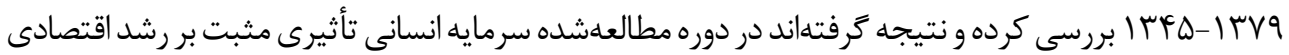

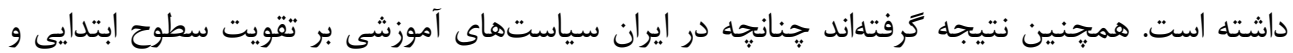

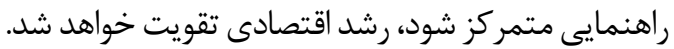

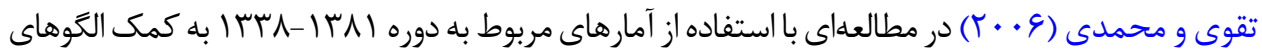

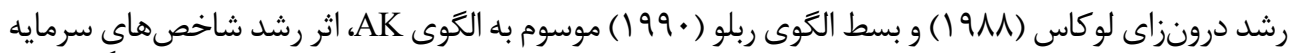

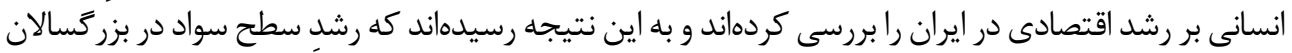

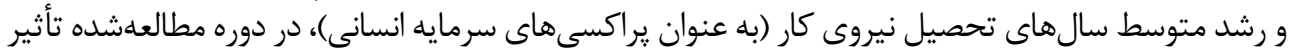

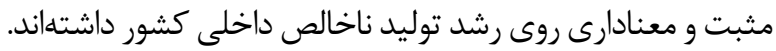

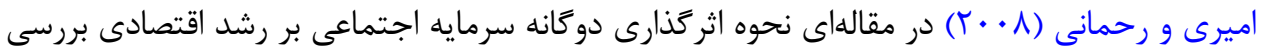

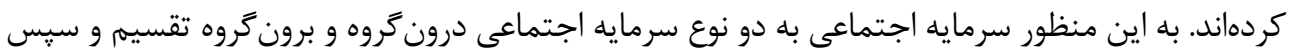

9. Mankiw, Romer and Weil 


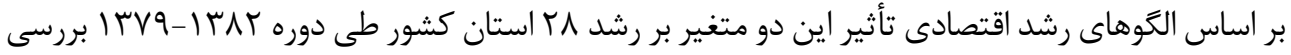

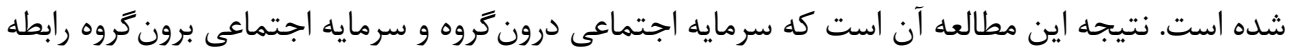

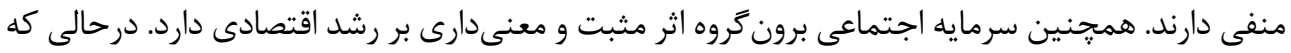

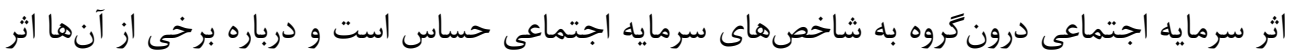
منفى بر رشد اقتصادى دارد.

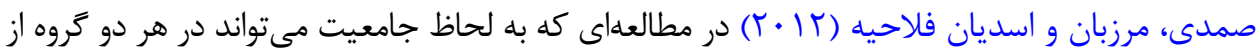

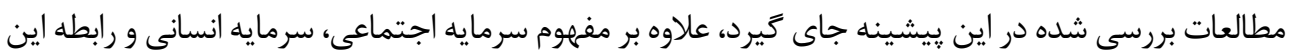

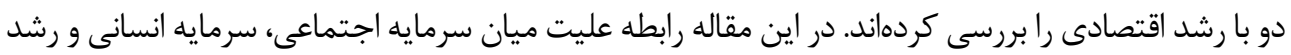

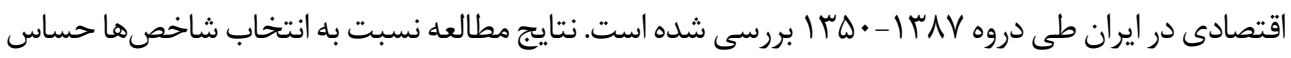
بودهاند، اما با اغلب شاخص دهاي إئ نماينده سرمايه اجتماعى اين نتايج حاصل شدهاند: سرمايه انسانى علت تشكيل

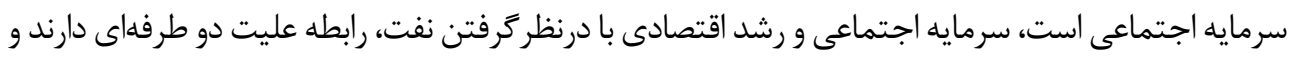

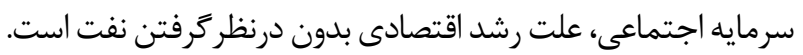

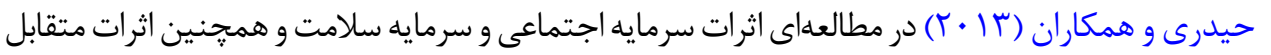

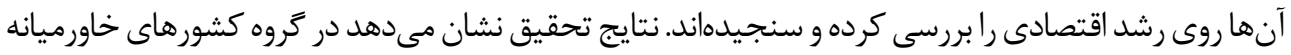

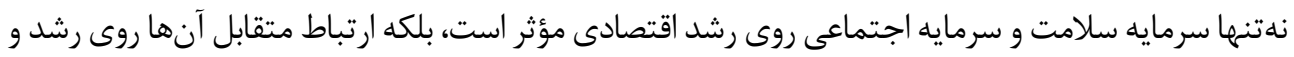
توسعه اقتصادى كشورها اثر مضاعفى دارد.

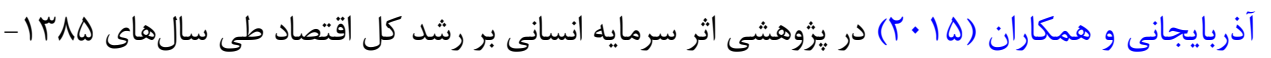

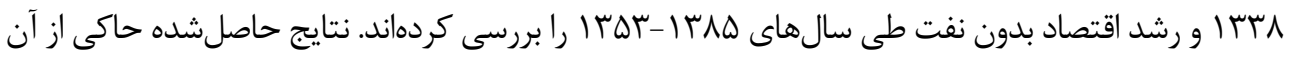

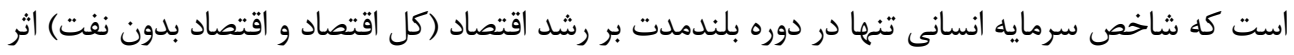

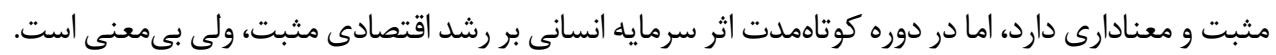

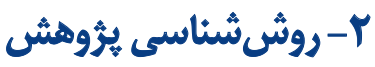

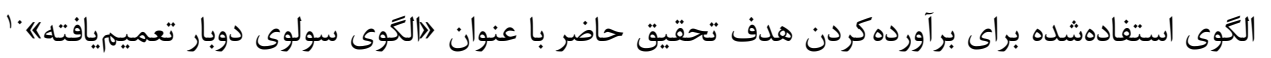

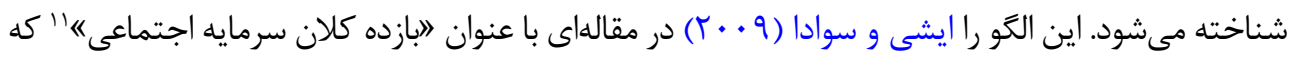

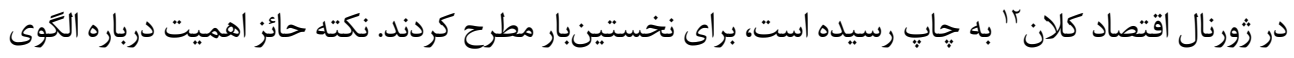

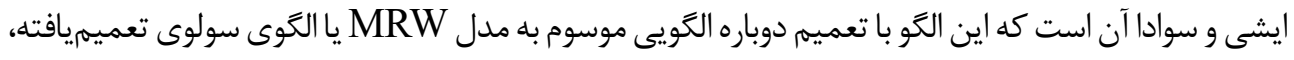

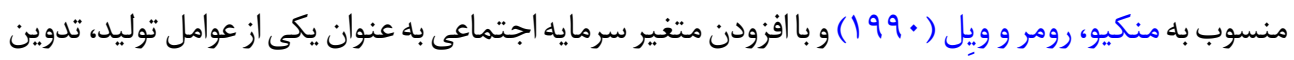
شده است. در الخوى ايشى و سوادا سه نوع سرمايه وجود دارد و توليد به صورت تابعى از سرمايه فيزيكى، سرمايه

10. Augmented-Augmented Solow Model

11. Aggregate returns to social capital

12. Journal of Macroeconomics 
انسانى، سرمايه اجتماعى، نيروى كار و فناورى در نظر گرفته مىشود (معادله شماره ؟).

$$
Y=f\left(K_{k}, K_{h}, K_{s}, L, A\right)
$$

يكى از فروض اساسى الگُى سولو، يعنى تكنولوزى خنثى از نوع هارود (كارافزا) در الخُوى ايشى و سوادا

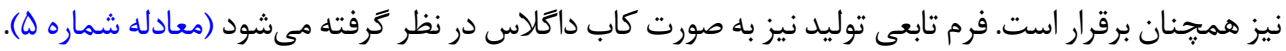

$$
Y=K_{k}^{\alpha} K_{h}^{\beta} K_{s}^{\gamma}(A l)^{1-\alpha-\beta-\gamma}
$$

به طورى كه:

$\alpha, \beta, \gamma \grave{O}[0,1)$

$\alpha+\beta+\gamma \grave{O}[0,1)$

در فرم تابعى فوق فرض بازده ثابت نسبت به مقياس توليد (همخنبودن از درجه () كه يكى از فروض اساسى

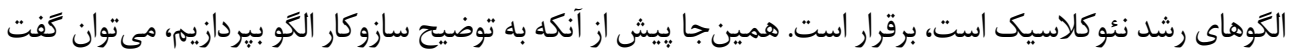

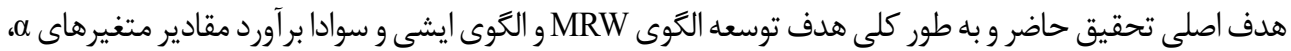

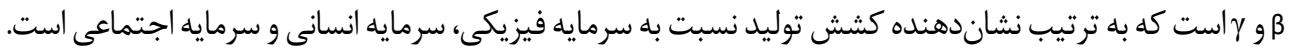

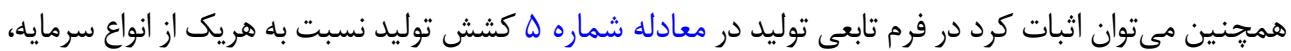

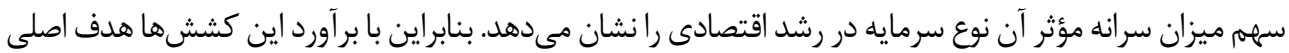

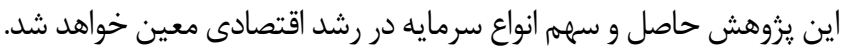

محورى ترين معادله در الكوى سولو معادله انباشت سرمايه فيزيكى است كه ميزان انباشت سرمايه سرانه مؤثر را به ريه

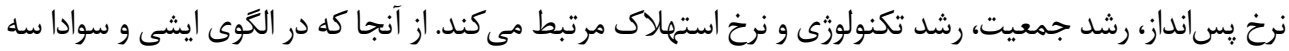

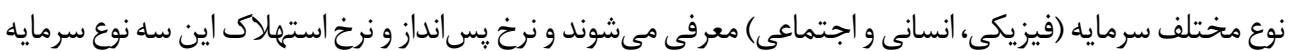

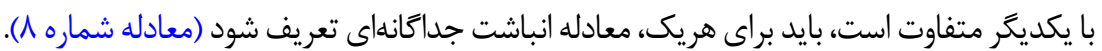

$\dot{\tilde{k}}_{i}=\operatorname{siy}-\left(n+g+\delta_{i}\right) \tilde{k}_{i}$

$i=k, h, s$

در معادله مذكور نرخ استتهلاك سرمايه از نوع i ام است و نرخ رشد جمعيت n و نرخ رشد تكنولوزى g هستند. 
همان گونه كه در الكوى اصلى سولو در وضعيت يكنواخت با تغييرات سرمايه فيزيكى سرانه مؤثر برابر با صفر

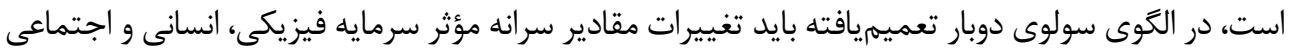

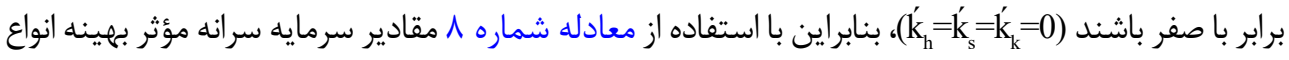
سرمايه در وضعيت يكنواخت

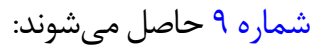

$\tilde{k}_{i}^{*}=\frac{s i \tilde{y}^{*}}{n+g+\delta_{i}} i=k, h, s$

اكر براى سادگى فرض كنيم كه نرخهاى استهلاك هر سه نوع سرمايه با يكديخر برابر باشند

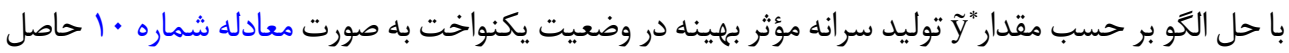

$$
\tilde{y}^{*}=\left[\frac{s_{k}^{\alpha} s_{h}^{\beta} s_{s}^{\gamma}}{(n+g+\delta)^{\alpha+\beta+\gamma}}\right]^{\frac{1}{1-\alpha-\beta-\gamma}}
$$

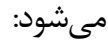

$$
\text { با كرفتن لكاريتم طبيعى از طرفين معادله شماره • (1، معادله شماره } 1 \text { إصل ماشىود: }
$$

$$
\ln \left(\frac{Y^{*}}{A L}\right)=\left[\frac{\alpha}{1-\alpha-\beta-\gamma} \ln \left(s_{k}\right)+\frac{\beta}{1-\alpha-\beta-\gamma} \ln \left(s_{h}\right)+\frac{\gamma}{1-\alpha-\beta-\gamma} \ln \left(s_{s}\right)-\frac{\alpha+\beta+\gamma}{1-\alpha-\beta-\gamma} \ln (n+g+\delta)\right]
$$

$$
\text { همجنين بر حسب توليد سرانه، معادله زير به دست مى آيد. }
$$

$$
\ln \left(\frac{Y^{*}}{L}\right)=a+g t+\frac{\alpha}{1-\alpha-\beta-\gamma} \ln \left(s_{k}\right)+\frac{\beta}{1-\alpha-\beta-\gamma} \ln \left(s_{h}\right)+\frac{\gamma}{1-\alpha-\beta-\gamma} \ln \left(s_{s}\right)-\frac{\alpha+\beta+\gamma}{1-\alpha-\beta-\gamma} \ln (n+g+\delta)+\varepsilon
$$

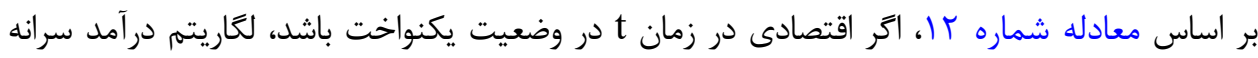

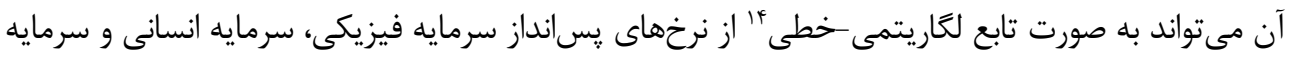

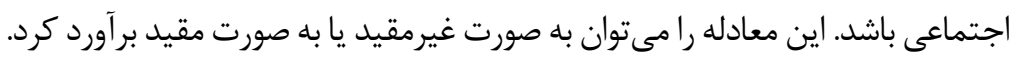

13. Steady-sate

14. Log-linear 


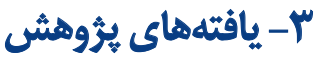

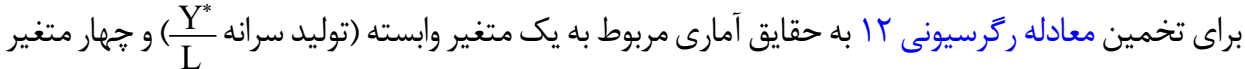

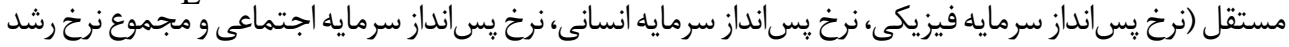

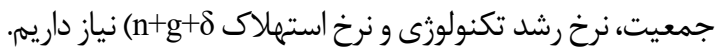

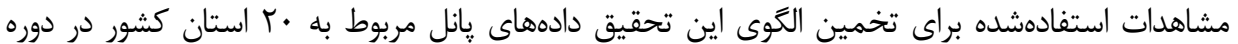

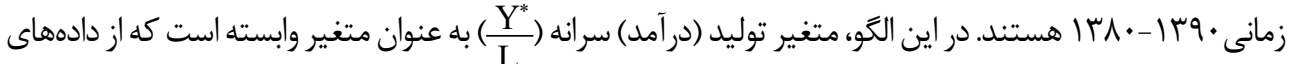

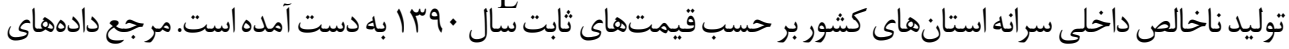

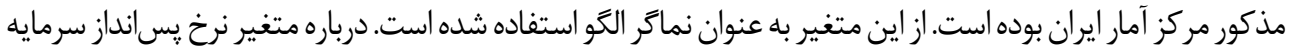

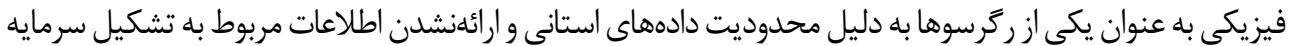

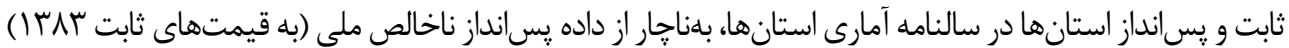

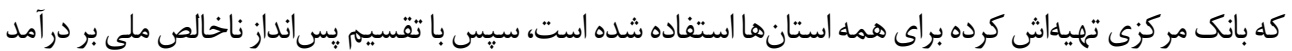

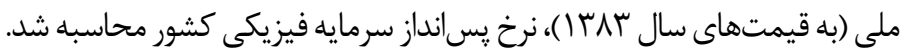

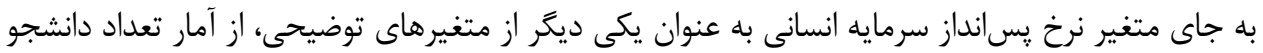

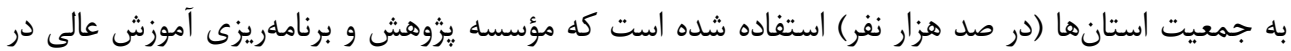

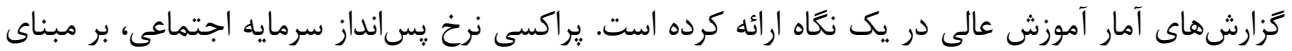

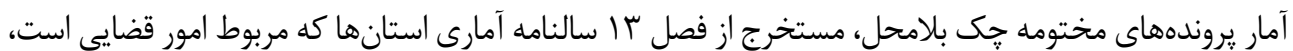

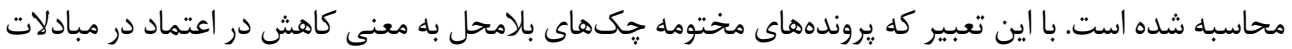

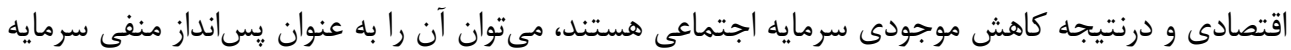

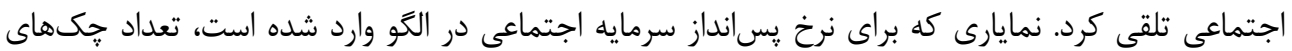

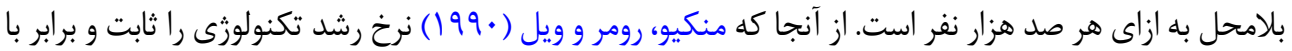

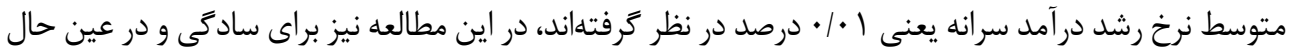

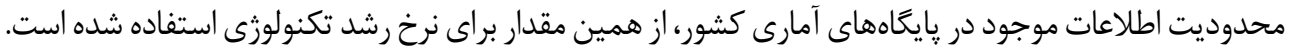

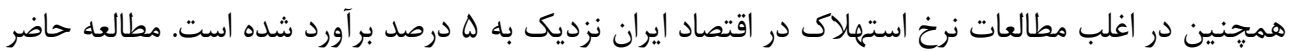

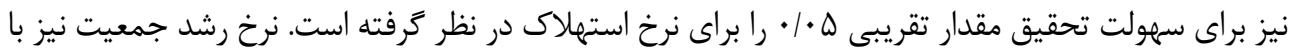

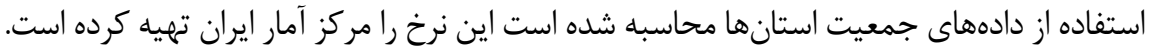

\section{"ا-1 - روش تخمين و تصريح الكوى رّترسيون}

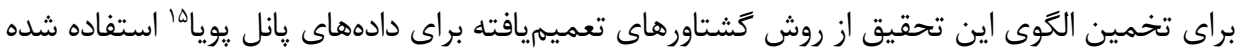

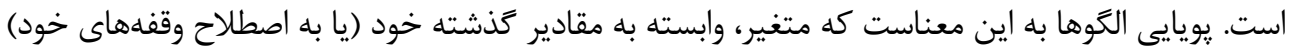


جدول ا. نئايج آزمونهاي ريشه واحد IPS و

\begin{tabular}{|c|c|c|c|}
\hline مرتبه اتباشتئى & آزمون ADF & آز آزون IPS & مثغير \\
\hline بر اساس هر دو آزمون (T) AR است. & $\begin{array}{c}\text { Stat= MTre } \\
\text { Prob=^/MFY } \\
\text { غيرساكن }\end{array}$ & 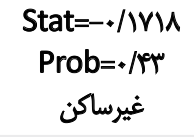 & $\ln \left(Y C A P_{t t}\right)$ \\
\hline بر الساس هر دو آزمون (I) AR است. & 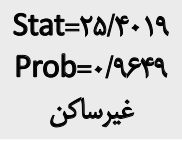 & 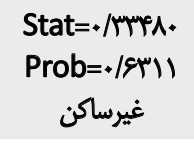 & $\ln \left(S K_{t}\right)$ \\
\hline 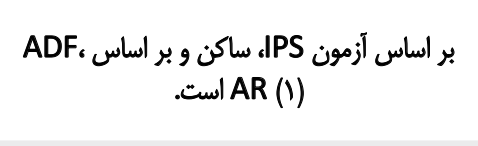 & $\begin{array}{c}\text { Stat }=r q / 1 \Delta q \\
\text { Prob }=* / 1 \Delta r \% \\
\text { غ غيرس }\end{array}$ & 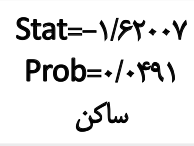 & $\ln (S H i)$ \\
\hline بر اساس آزمون IPS، غيرساكن و بر اساس است. & $\begin{array}{c}\text { Stat=PNeTVA } \\
\text { Prob=+/IRTa } \\
\text { Sus }\end{array}$ & 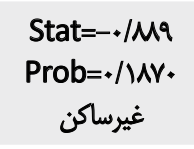 & $\ln \left(S S_{H t}\right)$ \\
\hline بر اساس هر دو آزمون، (IR (I) است. & 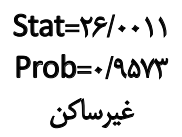 & 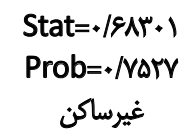 & $\ln \left(n_{t i t}+0.06\right)$ \\
\hline
\end{tabular}

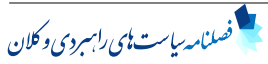

منبع: يافتههاي تحقيق

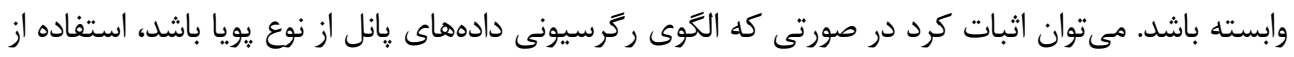

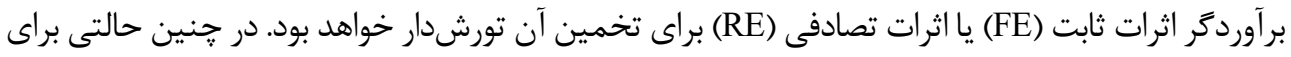

If جدول T. نتايج برآورد معادله

\begin{tabular}{|c|c|c|c|}
\hline سطح معنادارى & آماره تى & بوآورد & ركرسورها \\
\hline $.1 . .10$ & -T/MPITL. & $C_{1}=-\cdot / . Y Y q 9$. & $\operatorname{dln}\left(Y C A P_{i t}-1\right)$ \\
\hline 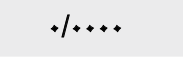 & -VIETQQ.1 & $C_{r}=-\cdot / \cdot 1 . .9 Y$ & trend \\
\hline$+\ldots$ & |A/Mrgl. & $C_{r}=+\cdot / \Delta V Y Y \wedge \&$ & $d \ln \left(S K_{t}\right)$ \\
\hline $.1 \ldots$ & $\Delta / r \cdot m a r$ & $C_{p}=+\cdot / \cdot r \Delta \cdot 19$ & $\ln \left(S H_{i t}\right)$ \\
\hline.$\cdots n$ & -TMYE..V & $C_{\Delta}=-\cdot / \cdot$ YVAVT & $d \ln \left(S S_{i t}\right)$ \\
\hline.$\ldots$ & - & $C_{8}=-1 / 118199$ & $-d \ln \left(n_{i t}+0.06\right)$ \\
\hline
\end{tabular}


جدول ب. نتايج أزمونهاى ريشه واحد LLC

\begin{tabular}{|c|c|c|c|}
\hline مرتبه النباشتّكي & PP آز & آز آزون LLC & متغير \\
\hline بر أساس أزمون LLC أزمون (I) ساكن و بر اساست & $\begin{array}{c}\text { Stat }=1 \varnothing / 9 r+\varnothing \\
\text { Prob=॰/999ه } \\
\text { غير ساكن }\end{array}$ & $\begin{array}{c}\text { Stat }=-\% / .118 \\
\text { Prob }=+1 \cdots \\
\text { wh }\end{array}$ & $\ln \left(Y C A P_{i t}\right)$ \\
\hline بر اساس هر دو آزمون ساكن أست. & $\begin{array}{c}\text { Stat }=r+\cdot 1 \cdot .9 \\
\text { Prob }=.1 \ldots .+ \\
\text { ساك }\end{array}$ & $\begin{array}{c}\text { Stat }=-r / A N \\
\text { Prob }=/ \cdots \cdots \\
\text { isl w }\end{array}$ & $\ln \left(S K_{t}\right)$ \\
\hline بر اساس هر دو آلزمون ساكن أست. & 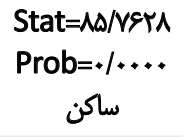 & $\begin{array}{c}\text { Stat }=-N \cdot 19 \\
\text { Prob }=.1 \cdots \\
\text { Slw }\end{array}$ & $\ln \left(S H_{i t}\right)$ \\
\hline 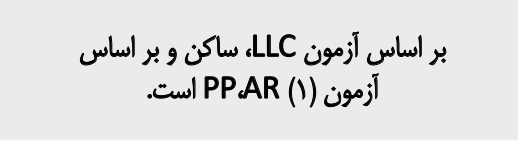 & $\begin{array}{c}\text { Stat=r\&/ares } \\
\text { Prob=ø/arqr } \\
\text { ساك }\end{array}$ & $\begin{array}{c}\text { Stat }=-N A E T H \\
\text { Prob }=+1 \ldots+. \\
\text { غيرسير }\end{array}$ & $\ln \left(S S_{l l}\right)$ \\
\hline بر اساس آزمون (1LC AR (LLC و بر اساس آزمون PP، & 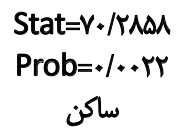 & 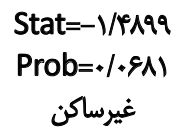 & $\ln \left(n_{t t}+0.06\right)$ \\
\hline
\end{tabular}

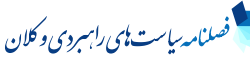

منبع: يافتههاي تحقيق

دستيابى به تخمينهاى بدون تورش مىتوانيم از روش گشتاور رهاى تعميميافته براى دادههاى يانل يويا استفاده كنيم كه نخستينبار آرلانو و بوند (1999 (1) مطرح كردند.

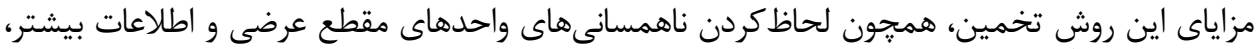

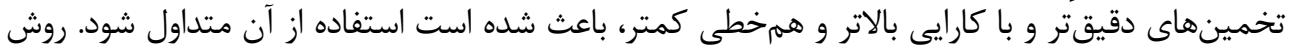

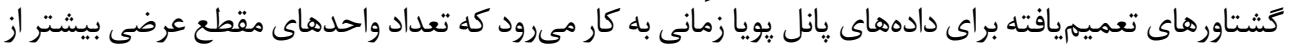

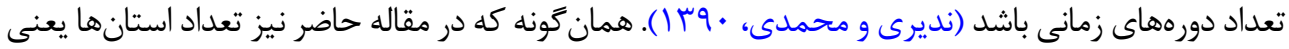

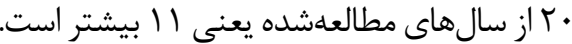

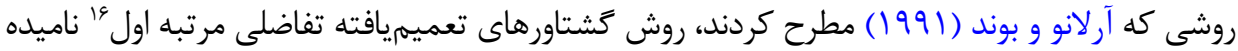

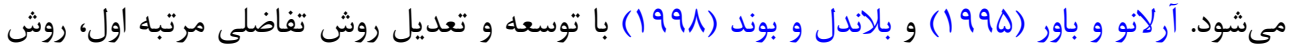

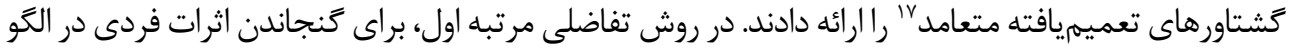

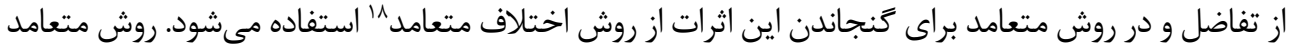

16. First Difference GMM

17. Orthogonal GMM

18. Orthogonal Deviation 
جدول F منتايج برآورد معادله

\begin{tabular}{|c|c|c|c|}
\hline سطح معنادارى & آماره تي & برآورد & رئرسورها \\
\hline $.1 .$. & $r \cdot 18811 r$ & $C_{1}=+\cdot T \& \wedge \cdot 9 \%$ & $\ln \left(Y C A P_{i t-1}\right)$ \\
\hline $.1++91$ & v/uif.. & $C_{Y}=+\cdot / \cdot V Y \wedge Y$ & trend \\
\hline$+1+\ldots$ & $\Delta / 1 V+9 \Delta 9$ & $C_{r}=+\cdot / M^{\prime} \mid \& \wedge T r$ & $\ln \left(S K_{t}\right)$ \\
\hline..$+ r V$ & r/.PTAY. & $C_{r}=+\cdot / \cdot Y \wedge \& 98$ & $\ln \left(S H_{H L}\right)$ \\
\hline$+1+\cdots+\infty$ & -ID/NDEV. & $C_{D}=-\cdot / M A V V Y$ & $d \ln \left(S S_{n}\right)$ \\
\hline$+\ldots+$ & $-11 \pi / T \Delta \cdot 9 \Delta$ & $C_{q}=-\cdot / \Delta 19 r \wedge V$ & $-\ln \left(n_{t t}+0.06\right)$ \\
\hline
\end{tabular}

21

منبع: يافتههاي تحقيق

نسبت به روش تفاضلى مزيتهايى دارد، از جمله اينكه دقت تخمين را بالا مىبرد و درجه آزادى كمترى از

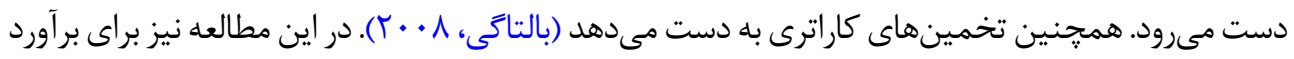

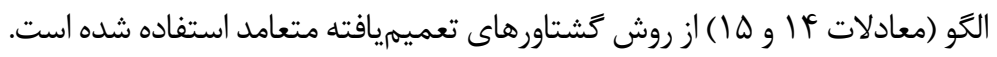

\section{ن}

در بخش تبيين الكو بيان شد كه معادله رگرسيون جا بايد برآورد شود و بر اساس نتايج آن ميزان تأثير

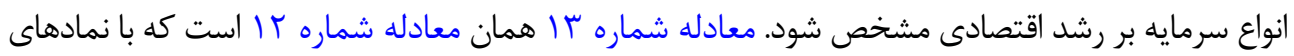

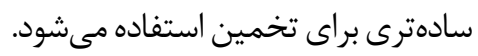

$$
\ln \left(Y C A P_{i t}\right)=C(1)+C(2) \cdot t+C(3) \cdot \ln \left(S K_{t}\right)+C(4) \cdot \ln \left(S H_{i t}\right)+C(5) \cdot \ln \left(S S_{i t}\right)-C(6) \cdot \ln \left(n_{i t}+0.06\right)+U_{i t}
$$

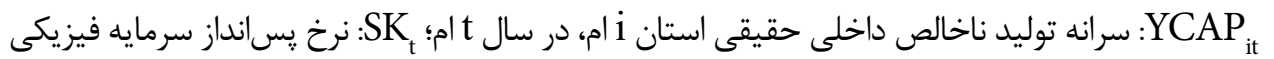

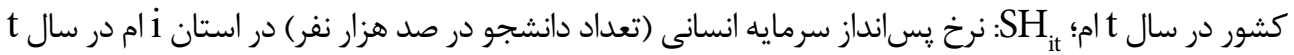

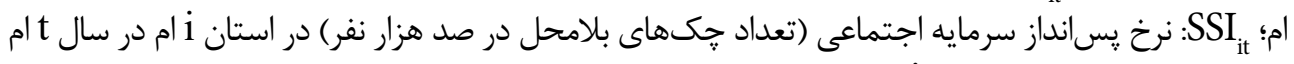
و

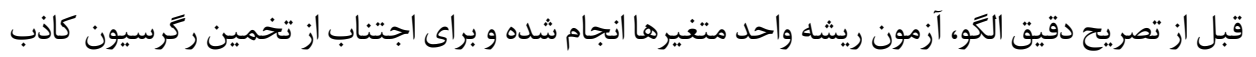

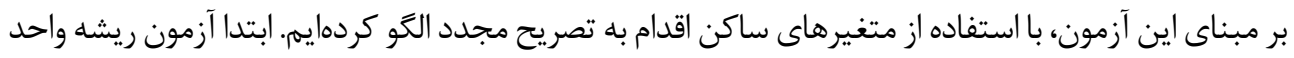




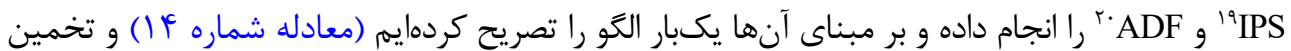

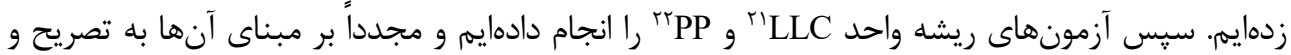

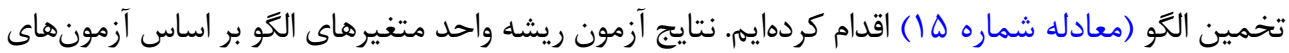

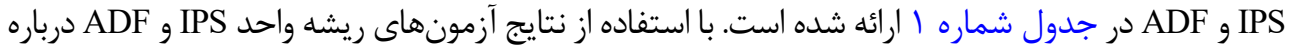
متغيرهاى الكو و تفاضل گيرى از متغيرهاى غيرساكن، مى توانيم الكو را به شكل زير تصريح كنيه:

همان گونه كه ييشتر توضيح داديم به اين دليل كه در سمت راست معادله شماره fl 1 وقفهاى از متغير

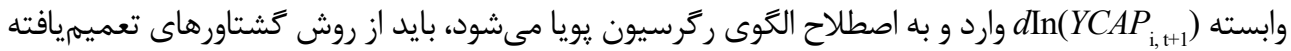

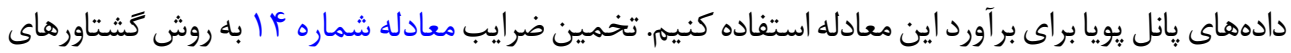

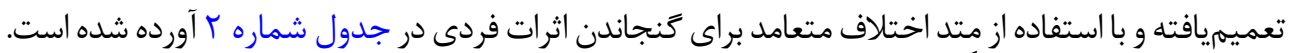
نتايج آزمون ريشه واحد متغيرهاى الكو بر اساس آزمونهاى LLC و PP در جدول شماره ب ارائه شده است.

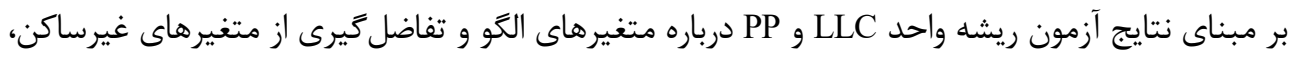
مى توانيم الكَو رابه شكل زير ازمون ريشه وتصريح كنيم:

$$
\ln \left(Y C A P_{i t}\right)=C(1) \cdot \ln \left(Y C A P_{i, t-1}\right)+C(2) \cdot t+C(3) \cdot \ln \left(S K_{t}\right)+C(4) \cdot \ln \left(S H_{i t}\right)+C(5) \cdot d \ln \left(S S_{i t}\right)-C(6) \cdot \ln \left(n_{i t}+0.06\right)+U_{i t}
$$

به دليل يويايى معادله شماره ها از روش تخمين كشتاورهاى تعميميافته براى آن استفاده مى كنيم.

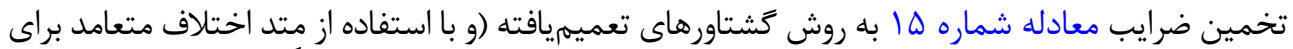
كنجاندن اثرات فردى) در جدول شماره f آورده شده است معاده

\section{ع- بحث و نتيجلَّيرى}

ع-1 - تحليل ثنتايج معادله رترسيونى (11)

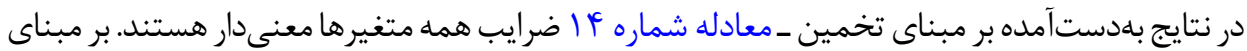

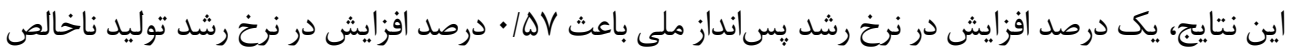

19. Im, Pesaran and Shin W-stat

20. ADF - Fisher Chi-square

21. Levin, Lin and $\mathrm{Chu}$

22. PP - Fisher Chi-square 


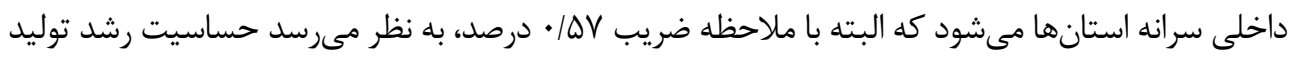

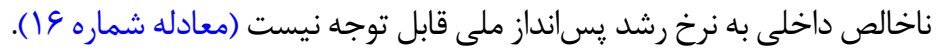

$$
\frac{d\left(d \ln \left(Y C A P_{i t}\right)\right)}{d\left(d \ln \left(S K_{i t}\right)\right)}=\frac{d\left(r_{Y C A P}\right)}{d\left(r_{S K}\right)}=0.57
$$

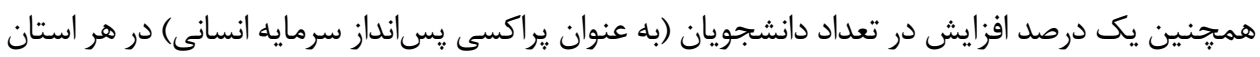

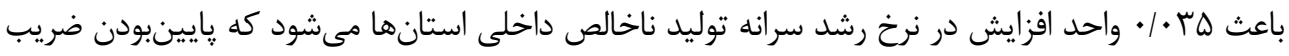

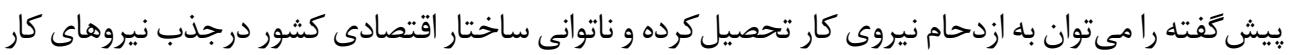

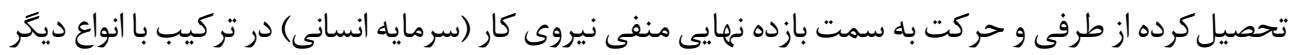

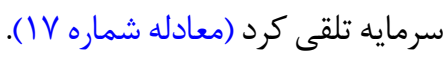

$$
\frac{\boldsymbol{d}\left(\boldsymbol{d l n}\left(\boldsymbol{Y C A P} \boldsymbol{P}_{i t}\right)\right)}{\boldsymbol{d l n}\left(\boldsymbol{S H}_{i t}\right)}=\frac{\boldsymbol{d}\left(\boldsymbol{r}_{\text {YCAP }}\right)}{\% \boldsymbol{d}(\boldsymbol{S H})}=0.035
$$

.IV

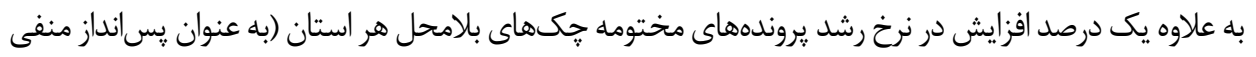

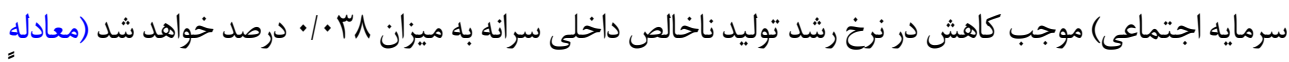

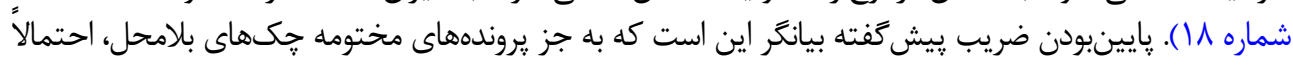

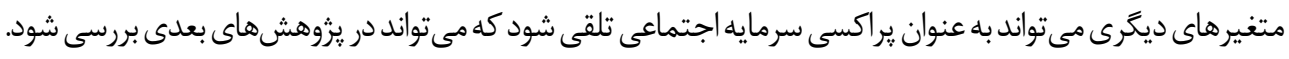

$$
\frac{d\left(d \ln \left(Y C A P_{i t}\right)\right)}{d\left(d \ln \left(S S_{i t}\right)\right)}=\frac{d\left(r_{Y C A P}\right)}{d\left(r_{S S}\right)}=-0.038
$$

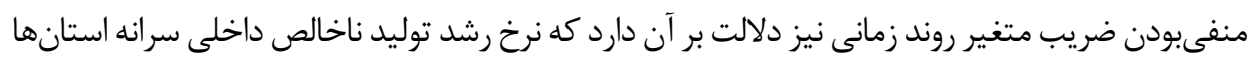

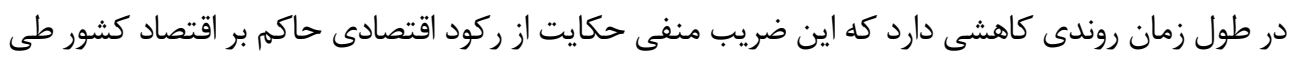
دوره بررسىشده دارد.

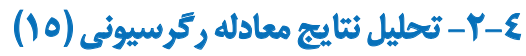

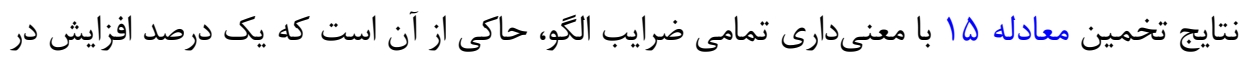

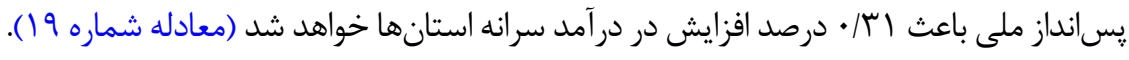

$$
\frac{d \ln \left(\boldsymbol{Y C A P} \boldsymbol{P}_{i t}\right)}{\operatorname{dln}\left(\boldsymbol{S K} K_{i t}\right)}=\frac{\% d(Y C A P)}{\% d(S K)}=0.31
$$


يك درصد افزايش در تعداد دانشجويان هر استان باعث 9 ؟ • • درصد افزايش در سرانه توليد ناخالص داخلى (معانى هر استان خواهد شد (معادله شماره • (Y).

$$
\frac{d \ln \left(Y C A P_{i t}\right)}{d \ln \left(S H_{i t}\right)}=\frac{\% d(Y C A P)}{\% d(S H)}=0.029
$$

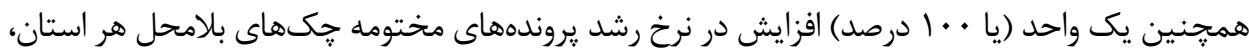

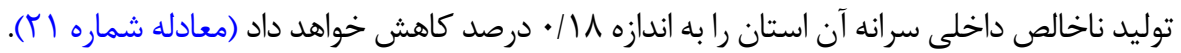

$$
\frac{d \ln \left(Y C A P_{i t}\right)}{d\left(d \ln \left(S S_{i t}\right)\right)}=\frac{\% d(Y C A P)}{d\left(r_{S S}\right)}=-0.18
$$

همان گونه كه انتظار مىرفت يسانداز هر سه نوع سرمايه در تعيين نرخ رشد و سطح رشد اقتصادى استانها،

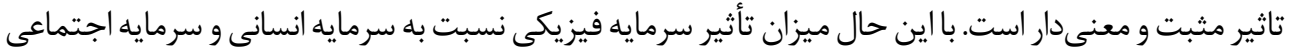

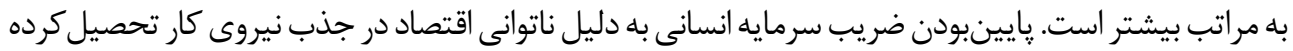

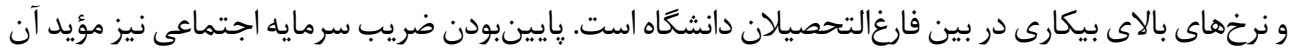

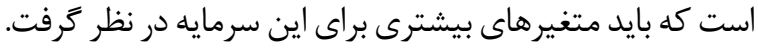

\section{مالاحظاث اخلاقي}

حامي مالي

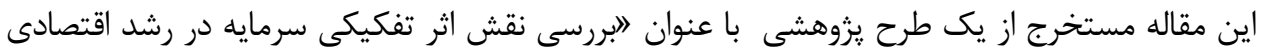

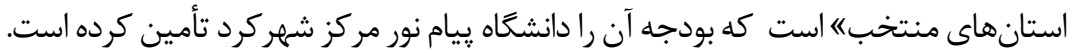

مشاركتنويسندكان

مديريت ڤروزه، يردازش ايده، تبيين مسئله، مدلسازى: يروانه كمالى دهكردى؛ مدلسازى، تجزيه و تحليل آمارى:

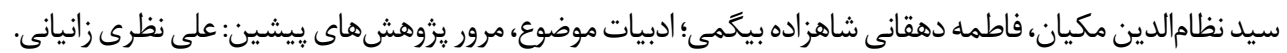

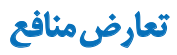

بنابر اظهار نويسندكًان، مقاله تعارض منافع ندارد. 
Abel, A. B., Mankiw, N. G., Summers, L. H., \& Zeckhauser, R. J. (1989). Assessing dynamic efficiency: Theory and evidence. The Review of Economic Studies, 56(1), 1-19. [DOI:10.2307/2297746]

Amiri, M., \& Rahmani, T. (2008). [Investigating the impact of internal and external social capital investments on economic growth in Iranian provinces (Persian)]. Semi-annual Journal of Iran's Economic Essays, 3(6), 111-52.

Arellano, M., \& Bond, S. (1991). Some tests of specification for panel data: Monte Carlo evidence and an application to employment equations. The review of economic studies, 58(2), 277-97.

Arellano, M., \& Bover, O. (1995). Another look at the instrumental variable estimation of error-components models. Journal of econometrics, 68(1), 29-51.

Azerbaijani, K., Moradpour Oladi, M., \& Najafi, Z. (2015). [Commercial liberalization and human capital on Iran's economic growth: 1385-1338 (Persian)]. Macroeconomic Research Journal, 9(18), 13-30.

Baltagi, B. (2008). Econometric analysis of panel data. Washington D. C.: John Wiley \& Sons.

Barro, R. J., \& Sala-i-Martin, X. (2004). Economic growth. $2^{\text {th }}$ Ed. Cambridge: MIT Press.

Blundell, R., \& Bond, S. (1998). Initial conditions and moment restrictions in dynamic panel data models. Journal of Econometrics, 87(1), 115-43.

Diamond, P. A. (1965). National debt in a neoclassical growth model. The American Economic Review, 55(5), 1126-50.

Domar, E. D. (1946). Capital expansion, rate of growth, and employment. Econometrica, Journal of the Econometric Society, 14(2), 137-47. [DOI:10.2307/1905364]

Ghaemi, V., Azarbaijani, K., Adibi Sadeh, M., \& Tavakoli, Kh. (2011). [Investigating the impact of social group capital on economic development in Iran's provinces (Persian)]. Rahbord Journal, 20(59), 243-70.

Hall, R. E., \& Jones, C. I. (1999). Why do some countries produce so much more output per worker than others? The Quarterly Journal of Economics, 114(1), 83-116. [DOI:10.1162/003355399555954]

Harrod, Roy F. (1939). An essay in dynamic theory. The Economic Journal, 49(193), 14-33. [DOI:10.2307/2225181]

Heidari, H., Faaljou, H., Nazariyan, E., \& Mohammadzadeh, Y. (2013). [Social capital, health capital and economic growth in the middle east countries (Persian)]. Quarterly Journal of Economic Growth and Development Research, 3(11), 57-74.

Ishise, H., \& Sawada, Y. (2009). Aggregate returns to social capital: Estimates based on the augmented augmented-Solow model. Journal of Macroeconomics, 31(3), 376-93. [DOI:10.1016/j.jmacro.2008.08.002]

Lucas Jr, R. E. (1988). On the mechanics of economic development. Journal of monetary economics, 22(1), 3-42.

Mankiw, N. G., Romer, D., \& Weil, D. N. (1990). A contribution to the empirics of economic growth. The Quarterly Journal of Economics, 107(2), 407-37. [DOI:10.3386/w3541]

Nadiri, M., \& Mohammadi, T. (2001). [Investigating the Effect of Institutional Structures on Economic Growth by GMM Dynamic Panel Data (Persian)]. Economic Modeling, 5(15), 1-24.

Nili, M. (2014). [Topics of advanced macroeconomics (Persian)]. Tehran: Sharif University of Technology.

Nili, M., \& Nafisi, Sh. (2004). [Human capital, education distribution of labor force and economic growth: the case of Iran (Persian)]. Iranian Journal of Economic Research, 5(17), 1-31. 
Ramsey, F. P. (1927). A contribution to the theory of taxation. The Economic Journal, 37(145), 47-61.

Romer, D. (2012). Advanced macroeconomics. New York: McGraw-Hill//rwin.

Romer, P. M. (1994). The origins of endogenous growth. The Journal of Economic Perspectives, 8(1), 3-22. [DOI:10.1257/ jep.8.1.3]

Sadeghi, M., \& Emadzadeh, M. (2004). [Estimating the human capital share in Iran's economic growth (1965-2000) (Persian)]. Iranian Journal of Economic Research, 17(5), 79-98.

Salehi, M. J. (2002). [The impact of human capital on Iran's economic growth (Persian)]. Quarterly Journal of Research and Planning in Higher Education, 8(1), 43-74.

Samadi, A. H., Marzban, H., \& Asadian Falahiyeh, K. (2012). [Human capital, social capital, and economic growth a case study of Iran's economy (1350-1350) (Persian)]. Quarterly Journal of Applied Economics Studies in Iran, 1(2), 145-76.

Solow, R. M. (1956). A contribution to the theory of economic growth. The quarterly Journal of Economics, 70(1), 65-94.

Taghavi, M, \& Mohammadi, H. (2006). [The effect of human capital on economic growth: Case of Iran (Persian)]. Journal of Economic Research, 6(22), 15-44. 